\title{
Helicopter-borne measurements of sea ice thickness, using a small and lightweight, digital EM system
}

\author{
Christian Haas ${ }^{\mathrm{a}, 1, *}$, John Lobach ${ }^{\mathrm{b}}$, Stefan Hendricks ${ }^{\text {a }}$, Lasse Rabenstein ${ }^{\text {a }}$, Andreas Pfaffling ${ }^{\mathrm{a}, 2}$ \\ a Alfred Wegener Institute for Polar and Marine Research, Bussestrasse 24, D-27570 Bremerhaven, Germany

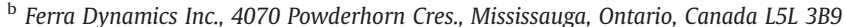

\section{A R T I C L E I N F O}

Article history:

Received 13 March 2007

Accepted 26 May 2008

\section{Keywords:}

Sea ice thickness

Frequency-domain electromagnetics (EM)

Helicopter EM (HEM) bird

\begin{abstract}
A B S T R A C T
Sea ice is an important climate variable and is also an obstacle for marine operations in polar regions. We have developed a small and lightweight, digitally operated frequency-domain electromagnetic-induction (EM) system, a so-called EM bird, dedicated for measurements of sea ice thickness. It is $3.5 \mathrm{~m}$ long and weighs only $105 \mathrm{~kg}$, and can therefore easily be shipped to remote places and operated from icebreakers and small helicopters. Here, we describe the technical design of the bird operating at two frequencies of $f 1=3.68 \mathrm{kHz}$ and $f 2=112 \mathrm{kHz}$, and study its technical performance. On average, noise amounts to $\pm 8.5 \mathrm{ppm}$ and $\pm 17.5 \mathrm{ppm}$ for $f 1$ and $f 2$, respectively. Electrical drift amounts to $200 \mathrm{ppm} / \mathrm{h}$ and $2000 \mathrm{ppm} / \mathrm{h}$ for $f 1$ and $f 2$, during the first $0.5 \mathrm{~h}$ of operation. It is reduced by $75 \%$ after $2 \mathrm{~h}$. Calibration of the Inphase and Quadrature ppm signals varies by 2 to 3\%. A sensitivity study shows that all these signal variations do affect the accuracy of the ice thickness retrieval, but that it remains better than $\pm 0.1 \mathrm{~m}$ over level ice in most cases. This accuracy is also confirmed by means of comparisons of the helicopter EM data with other thickness measurements. The paper also presents the ice thickness retrieval from single-component Inphase data of $f 1$.
\end{abstract}

Crown Copyright @ 2008 Published by Elsevier B.V. All rights reserved.

\section{Introduction}

Sea ice forms at the surface of polar waters due to cooling by low air temperatures. In September, during the peak of the Southern Hemisphere winter, sea ice covers approximately $10 \%$ of the world ocean surface. In spite of its large coverage, the thickness of sea ice ranges only between a few decimetres to a couple of meters. Locally, however, in pressure ridges, ice thickness can amount to more than $50 \mathrm{~m}$ as a result of rafting and ridging (Wadhams, 2000). As sea ice forms by thermodynamic processes, its thickness depends primarily on the surface energy balance, which is largely determined by air temperature, short- and long-wave radiation, winds, and ocean heat flux (Maykut, 1986). However, sea ice also moves as a consequence of forces exerted by winds and ocean currents. Therefore, pressure ridges of piled ice blocks above and under the ice form by rafting and ridging in regions of convergent ice drift. Consequently, sea ice floes in a given region are composed of larger areas of level ice with confined

* Corresponding author. Present address: Department of Earth and Atmospheric Sciences, University of Alberta, 1-26 ESB, Edmonton, Alberta, Canada T6G 2E3. Tel.: +1 780492 8171; fax: +1 7804922030.

E-mail addresses: Christian.Haas@ualberta.ca (C. Haas), shendricks@awi.de

(S. Hendricks), lrabenstein@awi.de (L. Rabenstein), andreas.pfaffling@ngi.no

(A. Pfaffling).

1 Present address: Department of Earth and Atmospheric Sciences, University of Alberta, 1-26 ESB, Edmonton, Alberta, Canada T6G 2 E3.

2 Present address: Norwegian Geotechnical Institute (NGI), PO Box 3930 Ullevaal Stadion, NO-0806 Oslo, Norway. regions of pressure ridges in between, and the sea ice thickness distribution is usually characterised by a strong mode representing the thickness and fractional coverage of level ice and a long tail towards larger thicknesses contributed by deformed ice (Haas, 2003, and Fig. 8 below).

Due to its bright surface and snow cover, sea ice plays an important role in the global radiation balance and climate. The ice-albedofeedback describes the accelerated warming and melting of ice as a consequence of small reductions in sea ice coverage (e.g. Hall, 2004). When sea ice retreats, more dark ocean area is exposed to the surface, thus enhancing absorption of solar radiation and subsequent warming of surface water. This in turn will increase the melting of sea ice, thus contributing to a positive feedback of sea ice retreat.

As most sea salt is expelled from the ice matrix during sea ice formation, sea ice also contributes to the densification of surface sea water, which leads to convection and enhances thermohaline ocean circulation. On the opposite end, when sea ice melts, fresh water is released into the ocean, leading to a more stable stratification.

The development of sea ice is therefore critically observed in the context of global climate change, and sea ice is considered as a climate indicator. Recently, sea ice coverage has strongly decreased in the northern hemisphere, in summer and winter (Meier et al., 2005; Stroeve et al., 2005). However, little is known about ice thickness changes.

The role of sea ice and its thickness is also important for offshore operations and shipping. Sea ice occurs every winter e.g. in the Sea of Okhotsk, Baltic and Caspian Seas, and Gulf of St. Lawrence. In these regions sea ice thickness information is of fundamental importance for 
operational purposes and marine safety as well as for the design of ships, offshore structures, and port facilities.

While sea ice area and extent have been well observed by satellites for more than 30 years, ice thickness is still poorly observed. Most observations come from military nuclear submarine operations or from scientific ocean moorings, where ice thickness has been measured by means of upward-looking sonar (Rothrock et al., 1999; Wadhams, 2000; Haas, 2003). Only since the 1980s, American and Canadian work has established the use of electromagnetic-induction (EM) sounding (Kovacs et al., 1987; Kovacs and Holladay, 1990).

Starting 2001, the German Alfred Wegener Institute for Polar and Marine Research (AWI) commenced with the operation of a purposebuilt, small and lightweight, frequency-domain EM bird with digital electronics, which was designed for systematic ice thickness measurements in the context of climate studies and polar oceanography (Fig. 2). It had to be small and lightweight to facilitate operations from helicopter decks of ice breakers with small helicopters, and to be easily shippable to remote places in the Arctic and Antarctic. In this paper, we describe the instrument and its operation, and present its main noise, drift, and calibration characteristics as observed during six summer and winter measurement campaigns between 2004 and 2006. We also review our 1D approach for the ice thickness retrieval, which uses only one channel of the EM data instead of the full set of measurements of the Inphase and Quadrature components of the EM signal (Haas et al., 2006; Pfaffling et al., 2007). Finally, the sensitivity of the thickness estimates to the accuracy of the instrument calibration will be presented.

\section{EM sea ice thickness sounding}

EM sea ice thickness sounding takes advantage of the fact that sea ice has a very low electrical conductivity, while sea water is a very good conductor. Typical conductivities of sea ice are 0 to $50 \mathrm{mS} / \mathrm{m}$ (Haas et al., 1997) and 2400 to $2700 \mathrm{mS} / \mathrm{m}$ for sea water. Therefore, a low-frequency, primary EM field generated by the transmitting coil of an EM system penetrates the sea ice almost unaffected, while it generates eddy currents in the sea water below the sea ice underside. In turn, these eddy currents induce a secondary EM field which propagates upwards through the sea ice and whose strength is measured with the receiving coil of the EM system. The strength of the secondary EM field is directly related to the distance $h_{\mathrm{w}}$ between the coils and the conductive sea water surface, which coincides with the ice underside. Normally, the height of the EM system above the ice surface $h_{\mathrm{i}}$ is measured by means of a laser altimeter. Ice thickness $Z_{\mathrm{i}}$ results then from the difference between the electromagnetically determined height above the water surface $h_{\mathrm{w}}$ and the height above the ice surface $h_{\mathrm{i}}$ measured with the laser (Fig. 1; Haas et al., 2006; Pfaffling et al., 2007):

$Z_{\mathrm{i}}=h_{\mathrm{w}}-h_{\mathrm{i}}$

Note that $Z_{\mathrm{i}}$ is the total ice thickness, i.e. the sum of snow plus ice thickness.

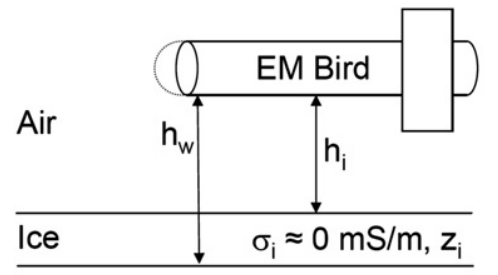

$$
\text { Water } \quad \sigma_{\mathrm{w}} \approx 2500 \mathrm{mS} / \mathrm{m}, \mathrm{z}_{\mathrm{w}}=\infty
$$

Fig. 1. Principle of EM thickness sounding, using a bird with transmitter and receiver coils and a laser altimeter. Ice thickness $Z_{\mathrm{i}}$ is obtained from the difference of measurements of the bird's height above the water and ice surface, $h_{\mathrm{w}}$ and $h_{\mathrm{i}}$, respectively. $h_{\mathrm{w}}$ is obtained with the assumption of a negligible ice conductivity $\sigma_{\mathrm{i}}$, known water conductivity $\sigma_{\mathrm{w}}$, and horizontal layering.
Table 1

Main characteristics of the AWI EM bird

\begin{tabular}{ll}
\hline Size $(\mathrm{m})$ & 3.5 long, 0.35 diameter \\
Weight $(\mathrm{kg})$ & 105 \\
Operation height $(\mathrm{m})$ & 10 to 20 \\
Flying speed $(\mathrm{knots})$ & 80 to 90 \\
Signal frequencies $(\mathrm{kHz})$ & $3.68(f 1)$ and $112(f 2)$ \\
Coil spacing $(\mathrm{m})$ & $2.77(f 1)$ and $2.05(f 2)$ \\
Sample frequency $(\mathrm{Hz})$ & $10(\mathrm{EM})$ and $100($ Laser $)$ \\
Tx dipole moment $\left(\mathrm{Am}^{2}\right)^{\mathrm{a}}$ & $54.5(f 1)$ and $5.3(f 2)$ \\
Power requirement $(\mathrm{W})$ & 400 \\
\hline
\end{tabular}

a Calculated as NIA: No. of turns*Current* Coil Area.

Based on the pioneering work of Kovacs et al. (1987),Kovacs and Holladay (1990), and Prinsenberg and Holladay (1993) using a helicopter-towed EM bird, EM sea ice thickness measurements have then been taken forward by Multala et al. (1996) and Prinsenberg et al. (2002). The former study has used a fixed-wing system where the transmitting and receiving coils were mounted at the wingtips of a Twin Otter air plane. Prinsenberg et al. (2002) have developed a fixedmounted helicopter EM system, where the EM coils are housed in a stinger in front of the helicopter.

In parallel to the technical developments in Canada and the US mentioned in Section 1, Liu and Becker (1990) and Liu et al. (1991) developed numerical 1D and 2D inversion algorithms for the ice thickness retrieval from the EM measurements, partially in real-time. Other sea ice studies used standard Marquart-Levenberg inversion (Rossiter and Holladay, 1994; Multala et al., 1996). However, the results of the inversion are critically dependent on the accuracy and stability of the calibration of the EM instrument, and on low noise characteristics, and can require extensive and tedious data editing. Therefore, we have developed an alternative 1D approach for the ice thickness retrieval, which uses only one channel of the EM data. This will be reviewed in detail in Section 5 and has also been described by Haas et al. (2006) and Pfaffling et al. (2007). As demonstrated by Haas et al. (2006), Pfaffling et al. (2007), and Pfaffling and Reid (2009-this issue) this approach yields quick and accurate ice thickness estimates of level ice in good agreement $( \pm 0.1 \mathrm{~m})$ with drill-hole validation measurements. Pfaffling et al. (2007) showed that the sensitivity of these ice thickness estimates to uncertainties of assumed ice and water conductivities is very small for the range of normally occurring ice thicknesses and ice conductivities.

In contrast to their high accuracy over level ice, EM measurements normally underestimate the maximum thickness of deformed ice (Kovacs et al., 1995; Reid et al., 2006). This is due to the footprint of EM measurements over those 3D structures, and due to the high conductivity of the ridge keel, which is composed of ice blocks and interconnected voids filled with sea water. The latter can lead to channelling effects of the electrical currents, preventing any deeper penetration of the EM field. As shown by Haas and Jochmann (2003), the underestimation of ridge thicknesses by EM measurements can therefore exceed $50 \%$ of coincident upward-looking sonar measurements. In this paper, we only focus on measurements over level ice.

\section{System components}

The AWI EM system consists of three main components (Fig. 3): The actual EM bird, the towing cable, and a few devices inside the helicopter for system control and power supply. Main characteristics are summarized in Table 1.

\subsection{EM bird}

The EM bird is $3.5 \mathrm{~m}$ long, has a diameter of $0.35 \mathrm{~m}$, and weighs $105 \mathrm{~kg}$ (Fig. 2). Inside the cylindrical kevlar shell, all components are mounted on a rigid plate which is accessible through two lid-closable holes. The plate can also be completely removed from the shell. The bird 


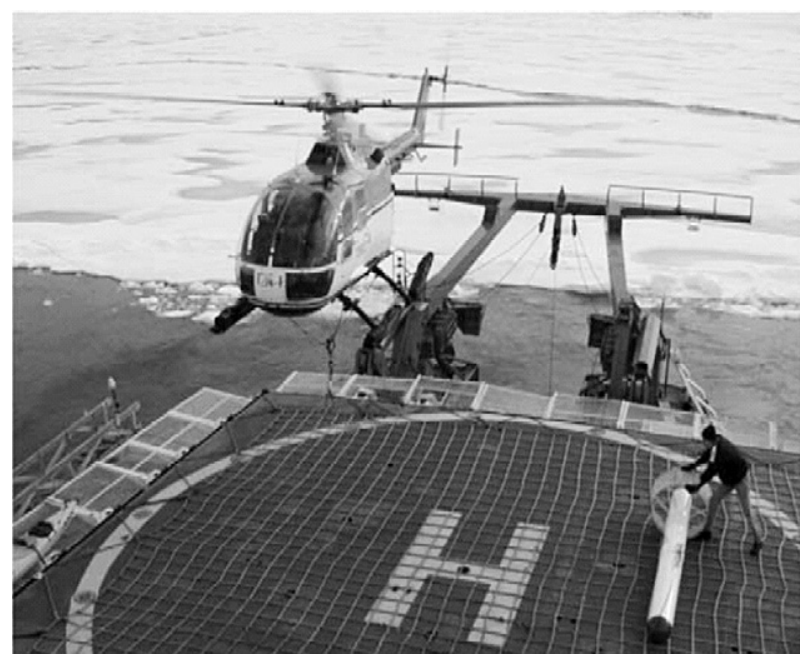

Fig. 2. AWI EM bird during take-off from the helicopter deck of an icebreaker, North Pole 2001.

operates at two frequencies of $3.68(f 1)$ and $112 \mathrm{kHz}(f 2)$. The frequencies were chosen to provide as much sensitivity to changes of ice thickness and ice conductivity as technically possible. As deviations of 1 or $2 \mathrm{kHz}$ do not significantly change the sensitivities, no efforts were undertaken to carefully adjust the resonance frequencies to a specific value. However, as shown by the inversion study of Pfaffling and Reid (2009this issue), an even higher second frequency would be required for a stable inversion of ice conductivity. Unfortunately this could not be realised due to technical reasons (see below). The coils for each frequency are mounted above and below the rigid plate. Fig. 3 shows the approximate positions of the coils of only one frequency. As usual with frequency-domain EM systems, for each frequency there is a transmitter coil Tx for signal generation, a receiving coil Rx for signal reception, a bucking coil for compensation of the primary EM field at the receiving coil, and a calibration coil which generates very accurate signals of known phase and amplitude if electrically connected. Tx-Rx coil spacing is 2.77 and $2.05 \mathrm{~m}$ for $f 1$ and $f 2$, respectively. At the bird's nose, there is a vertically downward-looking laser altimeter (cf. Fig. 1). A Differential Global Positioning System (DGPS) antenna is mounted on top of the shell. A computer in the centre of the rigid plate performs all required operations. It hosts $A / D$-converters for the analogue coil output signals, digital signal processing boards, serial communication cards, a network card, a GPS receiver, and a hard disk. The computer processes Inphase and Quadrature of the continuous harmonic signal with a sampling interval of $0.1 \mathrm{~s}$. The laser is operated at $100 \mathrm{~Hz}$. With a typical

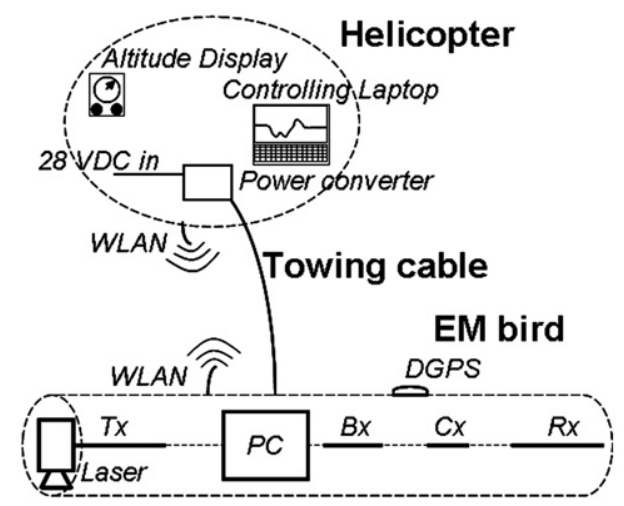

Fig. 3. Sketch of major components of AWI EM bird, consisting of transmitter coil (Tx), bucking coil $(\mathrm{Bx})$, calibration coil $(\mathrm{Cx})$, receiver coil $(\mathrm{Rx})$, computer $(\mathrm{PC})$, differential Global Positioning System (DGPS), wireless network (WLAN). Note that figure is not drawn to scale. flight speed of 80 knots, this corresponds to a point spacing of approximately $4 \mathrm{~m}$ for the EM data, and of $0.4 \mathrm{~m}$ for the laser data. The computer is connected to a wireless LAN network antenna, which provides communication with the operator in the helicopter (Section 3.3).

\subsection{Towing cable}

The towing cable is used to suspend the EM bird under the helicopter, and to transmit the required electrical power. We use tow cable lengths of 20 and $30 \mathrm{~m}$, respectively, depending on the size of the helicopter, and whether the bird needs to be landed on a small helicopter deck or on a large ice floe. With middle-sized helicopters, $20 \mathrm{~m}$ is sufficient to avoid disturbances of the measurements by conductive parts of the helicopter or by airflow turbulence.

\subsection{Devices inside the helicopter}

Three devices are hosted inside the helicopter: A DC/DC-power converter transforms the $28 \mathrm{VDC}, 400 \mathrm{~W}$ input voltage of the helicopter to approximately 200 VDC fed into the towing cable. All operations are performed with a standard laptop connected to the bird by wireless LAN. It is used to store and display the Inphase,
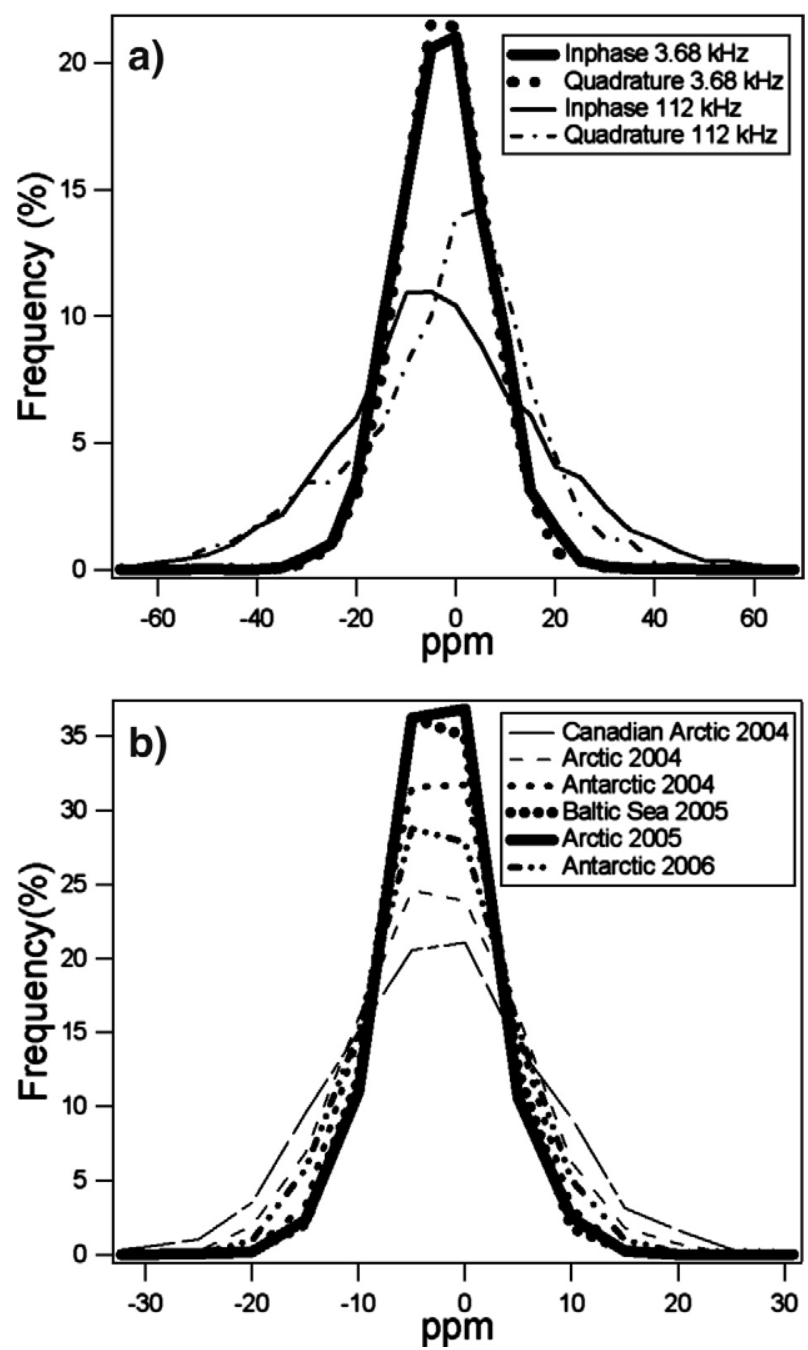

Fig. 4. Histograms of $40 \mathrm{~s}$ long sections of EM measurements of relative secondary EM field strength at altitudes greater than $100 \mathrm{~m}$. a) Inphase and Quadrature components of $f 1=3.68 \mathrm{kHz}$ and $f 2=112 \mathrm{kHz}$ measured in the Arctic during winter 2004 (cf. Fig. 4b). b) Inphase component of $f 1$ measured on different summer and winter campaigns between 2004 and 2006. 
Quadrature, laser, and GPS data in real-time, and to perform the required operations on the bird, e.g. nulling, phasing, and calibration. Via serial link, the raw laser data is forwarded to an analogue altimeter display visible for the pilot to control flying altitude. With this, pilots are comfortably flying the bird at typical altitudes of 10 to $20 \mathrm{~m}$ above the ice surface. Because of the bird's compactness and simplicity we have so far operated it from various different helicopter types like MD500, AS350, Bell 206, BO 105, Bell 212 and MI-8.

\section{Noise, drift, and stability of calibration}

The accuracy, sensitivity, and lateral resolution of EM measurements depend critically on the signal-to-noise ratio of the measurements, on the drift of the electronic components, as well as on the stability of the calibration. Fig. 4 shows typical histograms of measurements of the relative secondary EM field strength at high altitudes $>100 \mathrm{~m}$. At these heights, the relative secondary field strength of the Inphase component of $f 1$ is $<5 \mathrm{ppm}$, and $<1 \mathrm{ppm}$ for all other components. Therefore, the histograms are centred around approximately $0 \mathrm{ppm}$. However, it can be seen that there are large numbers of measurements with secondary field strengths significantly smaller or larger than $0 \mathrm{ppm}$. These measurements are due to noise. The noise distributions closely resemble Gaussian distributions (Fig. 4). As can be seen from their widths, the standard deviation of the noise amounts to approximately $\pm 9, \pm 8, \pm 20$, and \pm 15 ppm for the Inphase and Quadrature components of $f 1$ and $f 2$, respectively. However, the skewness of the distributions of the measurements at $f 2$ is due to the sporadic presence of spikes of unknown origin in those measurements. These also lead to the non-zero modes after nulling of the $f 2$ histograms in Fig. 4 a. Fig. $4 \mathrm{~b}$ shows that the noise of one component can vary between \pm 5 ppm (Arctic, summer 2005) and \pm 10 ppm (Arctic winter 2004) during different measurement campaigns.

Fig. 5 shows a $2.25 \mathrm{~h}$ long record of raw unphased complex voltage measurements at $f 1$. The typical sequence of measurements at high and low altitude can be seen. While the latter are performed to actually measure ice thickness, ascents to more than $100 \mathrm{~m}$ above sea level are made every 15 to 20 min to monitor and correct for electrical system drift in the absence of any significant signal from the sea water. Ideally, the measurements at high altitude should yield a voltage of $0 \mathrm{mV}$, if the compensation by the bucking coils was perfect. However, it can be seen that voltages of approximately $-200 \mathrm{mV}$ and $-230 \mathrm{mV}$ remain for the complex components of $f 1$, respectively, due to incomplete compensation. In addition, these zero-voltages are not constant, but vary for each ascent due to electrical drift. This offset and drift is removed by nulling with the data acquisition software during each ascent. For the drift correction, linear drift is assumed between ascents. The validity of this approach can be validated over sections of open water along the flight track (Sections 5 and 7).

Fig. 6 provides a summary of the typical drift of measurements representative of all campaigns between 2004 and 2006. It can be seen that there is no systematic drift behaviour. The same components might have a negative or positive drift, and the drift can be as high under summer conditions with warm air temperatures as under cold winter conditions. In fact, in all cases shown, the bird was already operated on the ground for $1 \mathrm{~h}$ or more to achieve thermal balance of the transmitter coil components before take-off. During take-off, the bird was switched off for as short a time as possible. Analysis of the curves in Fig. 6 shows that within the first $0.5 \mathrm{~h}$ of measurements, typical maximum drift rates are below $\pm 200 \mathrm{ppm} / \mathrm{h}$ for both components of $f 1$ and below $\pm 2000 \mathrm{ppm} / \mathrm{h}$ for $f 2$, respectively. After $2 \mathrm{~h}$ of operation, the drift is usually lower than $\pm 50 \mathrm{ppm} / \mathrm{h}$ for $f 1$ and $\pm 500 \mathrm{ppm} / \mathrm{h}$ for $f 2$, i.e. reduced by $75 \%$.

During the high altitude flight sections and after nulling, the calibration coils are electrically connected for a few seconds and generate well defined Inphase and Quadrature voltage offsets (cf. spikes in Fig. 5). The absolute value of the calibration signal has been both calculated (Fitterman, 1998) and verified by means of flights over open sea water with a precisely known conductivity. The measured strength of the calibration voltage offsets is first used to phase the raw complex voltage components and then to convert the voltage measurements into ppm. Typical values of the calibration coefficients derived over the period of our 6 campaigns were $95.27 \pm 1.98 \mu \mathrm{V} / \mathrm{ppm}$, $97.76 \pm 1.45 \mu \mathrm{V} / \mathrm{ppm}, 27.06 \pm 0.64 \mu \mathrm{V} / \mathrm{ppm}$, and $32.51 \pm 0.93 \mu \mathrm{V} / \mathrm{ppm}$ for the Inphase and Quadrature signals of $f 1$ and $f 2$, respectively. The standard deviations of the calibration coefficients reflect some drift of the calibration constant, but results also from the noise superimposed on the short calibration signals. The values show that the calibration has an uncertainty of less than $\pm 2 \%$ for $f 1$, and of approximately $\pm 3 \%$ for $f 2$. These are equivalent to uncertainties of $\pm 2 \%$ and $\pm 3 \%$ in the Gain of $f 1$ and $f 2$, and less than $1^{\circ}$ in the Phase.

\section{Ice thickness retrieval}

As also shown by Haas et al. (2006) and Pfaffling et al. (2007), ice thickness can be retrieved from one component of the complex EM signal alone if the conductivities of ice and water are known within certain bounds. For normal sea water with conductivities between 2000 and $2800 \mathrm{mS} / \mathrm{m}$, we invert only measurements of the Inphase component of $f 1$, as this is the strongest signal, and has also the lowest noise (Fig. 4) and smallest drift (Fig. 6). However, for brackish water of a few hundred $\mathrm{mS} / \mathrm{m}$ only, like, e.g. in the Baltic and Caspian Seas, the

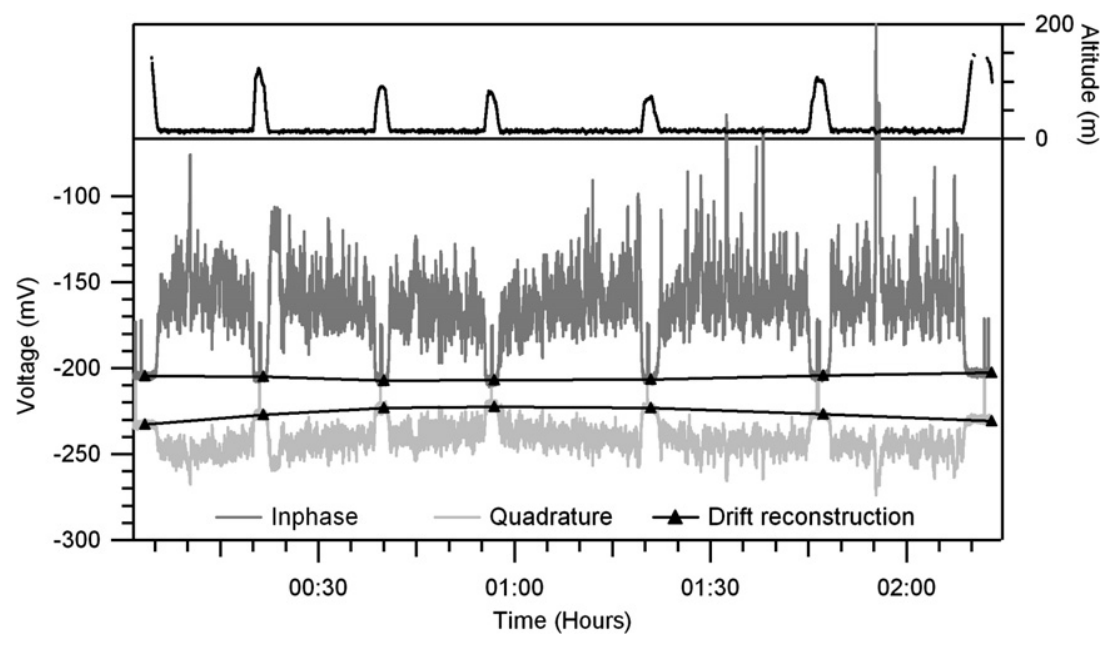

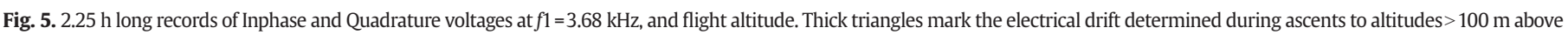
the sea surface. Note variations of high altitude measurements due to noise (cf. Fig. 4). Singular spikes during high altitude flights are due to calibration signal induced by calibration coils. 

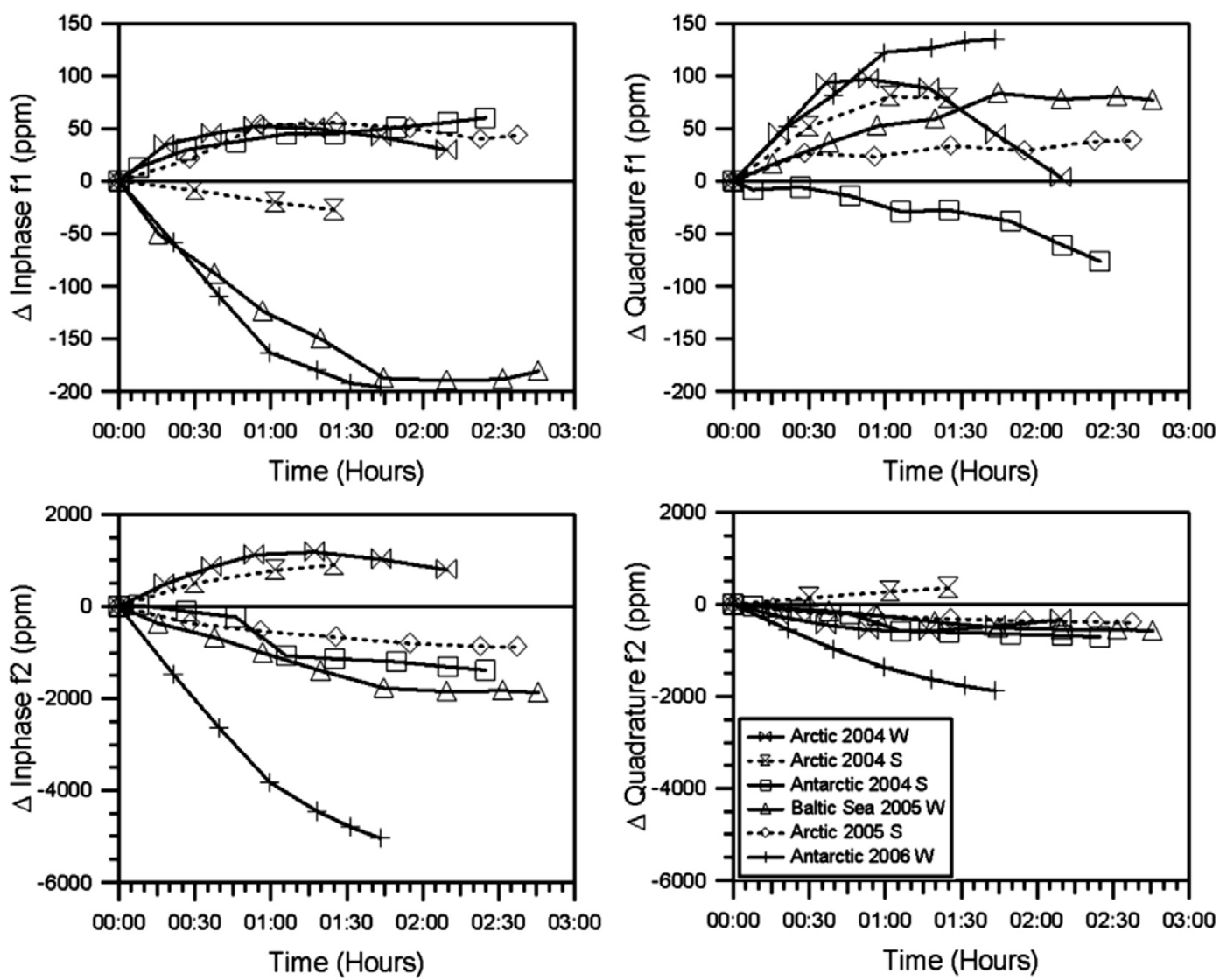

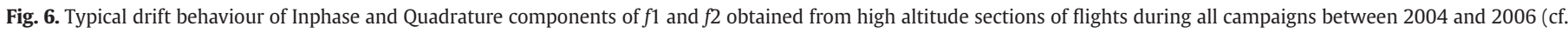
example in Fig. 5). Measurements are split into winter (W, solid lines) and summer campaigns (S, stippled lines).

Inphase of $f 2$ is the strongest signal and can be used as well (Haas, 2004, 2006; Pfaffling et al., 2007). The method is described in detail below.

Fig. 7 shows the relationship between bird height above the ice surface and measured and modelled EM responses for a flight over the Lincoln Sea, a marginal sea of the Arctic Ocean north of Ellesmere Island in Canada. Data and model show the Inphase response of $f 1$. The model results (Ward and Hohmann, 1988) have been computed for open water (ice thickness $0 \mathrm{~m}$ ) with a sea water conductivity of $2500 \mathrm{mS} / \mathrm{m}$, representative of in-situ salinity measurements. The model curve provides the general means of computing the height of the bird above the water surface $h_{\mathrm{w}}$ or ice underside from a measurement of Inphase EM field strength at a certain height above the water (Fig. 1; Haas, 1998). Measurements at different heights are obtained because the altitude of the helicopter and bird vary between 10 and $25 \mathrm{~m}$ during the flight (Figs. 7 and 8). The data can be separated into two sections: while open water measurements at different bird heights agree well with the model curves, the presence of sea ice leads to a reduction of the measured EM signal at a given laser height (Fig. 7). Therefore the scattered cloud of data points below the model curve represents measurements over ice. Ice thickness is computed by subtracting the laser height measurement over sea ice from the model curve (Haas, 1998). It can also be visually estimated from the horizontal distance between each EM measurement and the model curve (Fig. 7). The thickness computation assumes a negligible sea ice conductivity of $<20 \mathrm{mS} / \mathrm{m}$, which is likely for the multiyear ice in the study region (Haas et al., 1997; Pfaffling et al., 2007).

Fig. 8 illustrates the two steps of determining the height above the ice and water surfaces $h_{i}$ and $h_{w}$, and obtaining ice thickness from the difference of these measurements. The example is from the Transpolar Drift in August 2001. Fig. 8c shows the thickness distribution computed from the resulting ice thickness profile with a bin width of $0.1 \mathrm{~m}$. The modes of the distribution represent the fraction of open water along the profile, first-year ice with a modal thickness of $1.2 \mathrm{~m}$, and $2 \mathrm{~m}$ thick second and multiyear ice.

Due to the uncertainty of the calibration explained in Section 4, sometimes a slight recalibration of Inphase and Quadrature components, $I$ and $Q$ of the chosen frequency, is required during postprocessing, after drift correction and before ice thickness can be calculated as described above (Figs. 7 and 8). The Gain is corrected manually by aligning the open water measurements of both Inphase

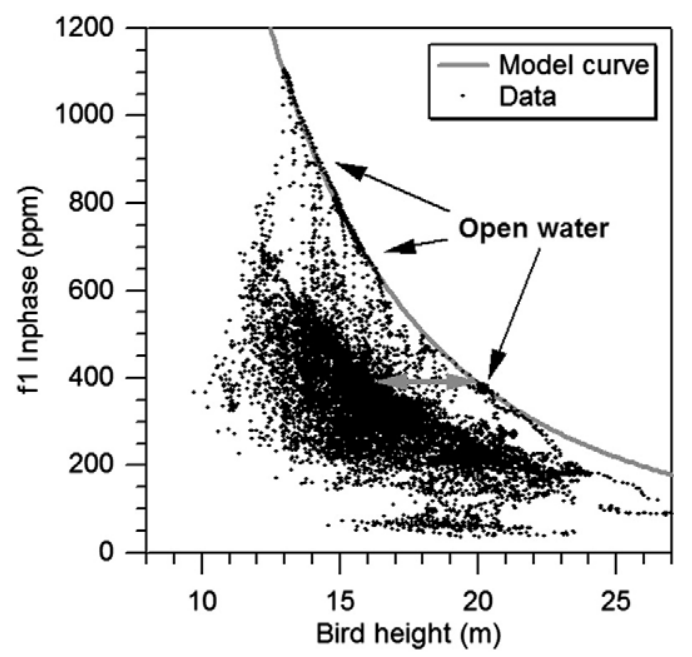

Fig. 7. Inphase component of relative secondary field strength of $f 1=3.68 \mathrm{kHz}$ versus bird height $h_{\mathrm{i}}$ (Fig. 1). A model curve for open water with a conductivity of $2500 \mathrm{mS} / \mathrm{m}$ and data over a typical ice surface with some leads are shown. The horizontal arrow illustrates how ice thickness $(4 \mathrm{~m})$ is obtained for a single data point from the difference between $h_{\mathrm{i}}$ and the model curve $h_{\mathrm{w}}$ for a given EM field strength (see Section 5; Fig. 1; Eq. (1)). 
a)

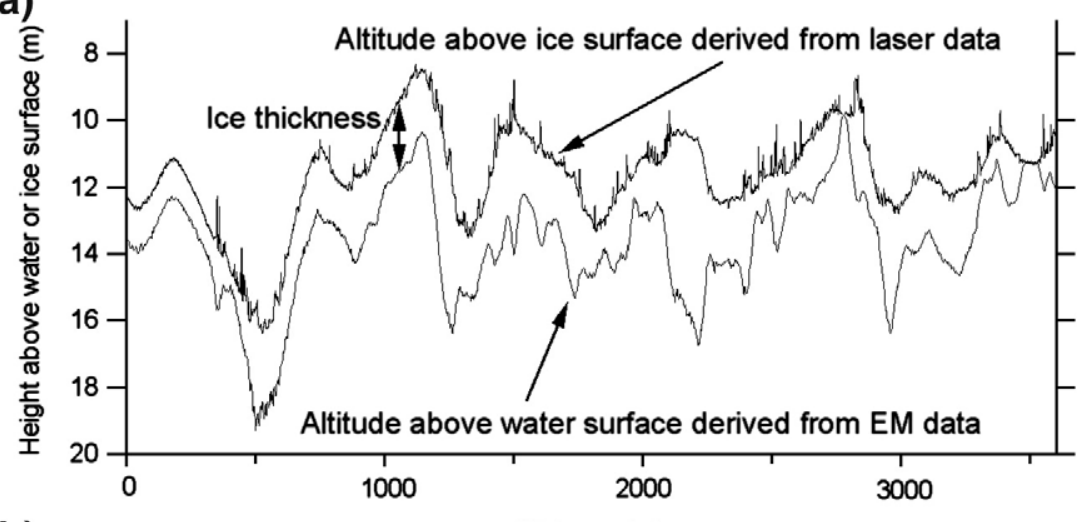

b)
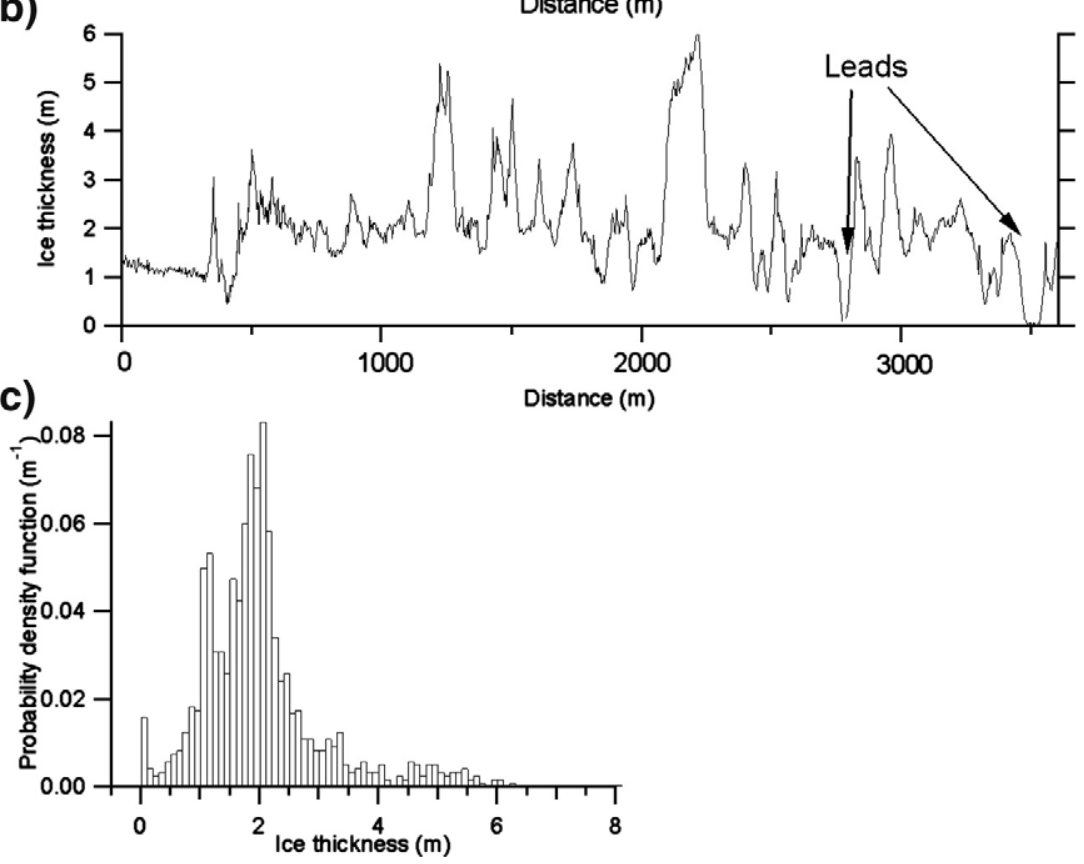

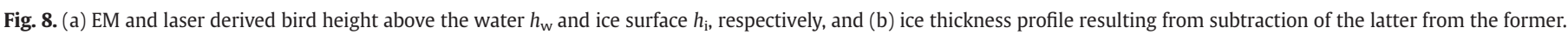
(c) Resulting thickness distribution.

and Quadrature components visually with the model curves for open water. The Phase is adjusted by aligning the measurements with modelled $I$ and $Q$ responses in a Phasor diagram, a cross-plot of $I$ and $Q$ (Pfaffling and Reid, 2009-this issue). The recalibration of Inphase, $I_{\text {recal }}$, and Quadrature, $Q_{\text {recal }}$, is performed by changing the Gain $A$ and Phase $P$ by $\Delta A$ and $\Delta P$ according to

$$
\begin{aligned}
& I_{\text {recal }}=A_{\text {recal }} * \cos \left(P_{\text {recal }}\right) \\
& Q_{\text {recal }}=A_{\text {recal }} * \sin \left(P_{\text {recal }}\right)
\end{aligned}
$$

Where $A_{\text {recal }}=A^{*}(1+\Delta A)$ and $P_{\text {recal }}=P+\Delta P . A$ and $P$ are derived from the original measurement of $I$ and $Q$ according to

$A=\operatorname{SQRT}\left(I^{2}+Q^{2}\right)$

and

$$
P=\operatorname{atan}(Q / I) \text {. }
$$

Typical values resulting from the recalibration range between 1.00 to 1.03 for $(1+\Delta A)$ and $0^{\circ}$ to $3^{\circ}$ for $\Delta P$, slightly exceeding the uncertainty of the calibration coefficients described in Section 4. This deviation is due to other additional factors determining the agreement with the model curves, including the correct knowledge of the seawater conductivity.

\section{Accuracy}

Noise, drift, and accuracy of the calibration affect the accuracy of the electromagnetically derived height above the water surface $h_{\mathrm{w}}$ and therefore the ice thickness calculation (Eq. (1)). The dependence of $h_{\mathrm{w}}$ on variations of noise, drift and accuracy of the calibration is shown in Fig. 9 for the Inphase component $I$ of $f 1$. For an ice thickness of $0 \mathrm{~m}, I$ agrees with the model curve for open water, and application of Eq. (1) correctly results in an ice thickness of $0 \mathrm{~m}$. $I$ has subsequently been varied by a constant offset of 5 and $10 \mathrm{ppm}$, by variable gain of 1.01 to 1.02 , and by a phase shift of 1 to $3^{\circ}$, according to the variations observed and described in Sections 4 and 5. The resulting deviations from an ice thickness of $0 \mathrm{~m}$ show the inaccuracy due to the uncertainty of the respective parameter.

As can be seen from Fig. 9, the errors resulting from noise and insufficient drift correction, as well as from inaccurate gains and phases are all dependent on the flying height above the water surface. For offsets of the Inphase component of $f 1$ of $10 \mathrm{ppm}$, the error exceeds $0.1 \mathrm{~m}$ for flying heights above $17 \mathrm{~m}$. Gain variations of between 0.99 and 1.01 result in thickness errors of less than $0.1 \mathrm{~m}$. The thickness retrieval is least sensitive on variations of phase, where variations of $\pm 2^{\circ}$ result in errors of about $0.1 \mathrm{~m}$. In summary, we conclude that the observed errors caused by the normal range of 


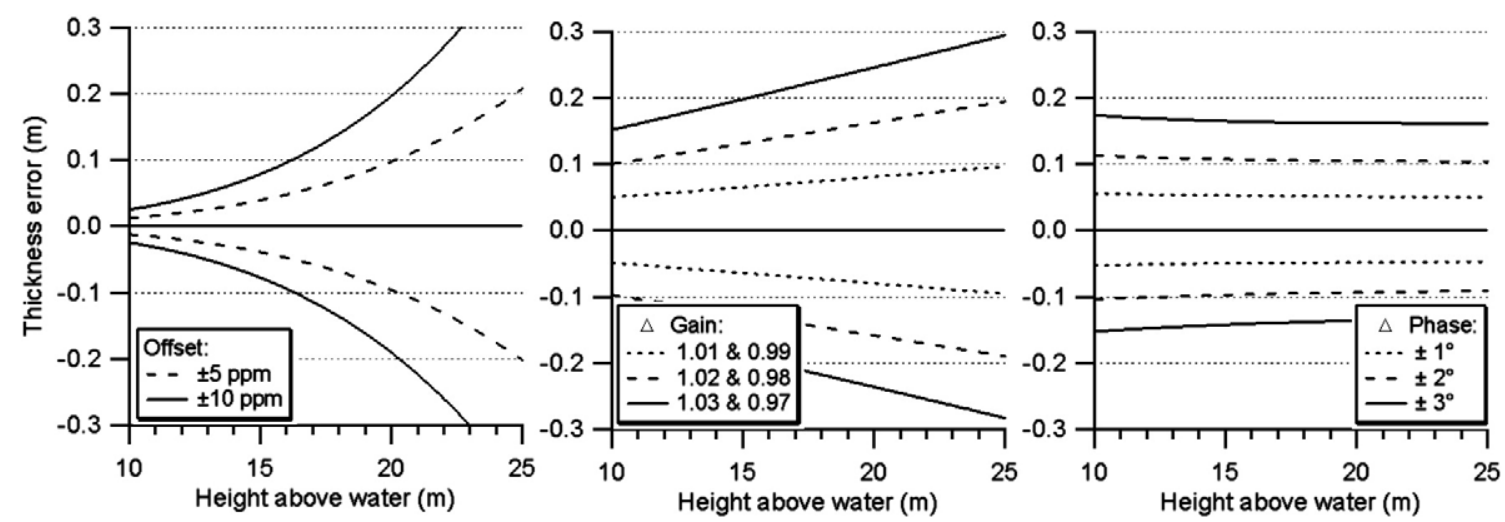

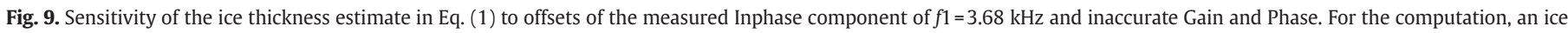
thickness of $0 \mathrm{~m}$ was taken and the panels show the difference between the true thickness and the thickness resulting from wrong offset, Gain and Phase.

noise, insufficient drift correction, and inaccurate calibration shown above all result in thickness errors of less than $\pm 0.1 \mathrm{~m}$. These may partially compensate each other, but can also add up in worst cases.

Finally, we compare ice thicknesses derived by means of HEM surveying with ice thicknesses derived by other means. Reid et al. (2006) and Pfaffling et al. (2007) have shown a good agreement within $\pm 0.1 \mathrm{~m}$ between extensive drill-hole and HEM measurements along the same profile. In Fig. 10, we compare thickness distributions derived by means of HEM and ground-based EM surveying over the same regions of Arctic and Antarctic sea ice. The ground-based profiles have been obtained on individual ice floes using a Geonics EM31 instrument (Haas et al., 1997). The histograms show the generally good agreement between both measurements. While most deviations can be explained by the largely different sample numbers and non-coincident profiles, characteristic modes can be found in both data sets in close agreement. In Fig. 10a, both histograms show a mode of $1.6 \mathrm{~m}$ representing firstyear ice (Haas et al., 2006). Similarly in Fig. 10b, $1.2 \mathrm{~m}$ thick first-year ice resulted in clear modes in both data sets, disagreeing by only $0.1 \mathrm{~m}$ (Haas et al., 2008). Both distributions also have local maxima at 2.6 and $2.9 \mathrm{~m}$, representing thick first-year and second year ice of the same origin.

All thickness distributions in Figs. 8 and 10 show rather narrow thickness modes less than $0.2 \mathrm{~m}$ wide for profile sections over open water and uniform first-year ice. This, as well as the results presented above, leads us to the conclusion that our ice thickness estimates have an accuracy of at least $\pm 0.1 \mathrm{~m}$.

\section{Discussion and conclusions}

We have presented the design and characteristics of a purpose-built, small and lightweight digital EM bird for sea ice thickness measurements, and have summarized our approach to compute sea ice thickness from single-component EM data. This approach was taken because it is largely independent of effects of sea ice conductivity (Pfaffling et al., 2007), and because it provides as accurate ice thickness results as a full geophysical inversion using all EM channels (Pfaffling and Reid, 2009this issue). In addition, its accuracy can easily be verified by plotting the EM signal versus laser height as in Fig. 7.

In this paper, we show that the errors resulting from system properties like noise, drift, and accuracy and stability of the calibration remain mostly below $\pm 0.1 \mathrm{~m}$ of ice thickness. Pfaffling et al. (2007) show that variations of sea ice conductivity result in ice thickness uncertainties of the same order. However, there are additional error sources e.g. from bird pitch and roll (Fitterman and Yin, 2004) not discussed here. These are due to both, changes of the electromagnetic dipole orientation with respect to the water surface, as well as due to slant angle changes of the laser altimeter. However, for roll angles of $<<10^{\circ}$ typical for normal flight patterns along straight lines with little wind, and for the operating altitude of our bird of 10 to $20 \mathrm{~m}$, these do not result in much larger errors than those described here (Holladay et al., 1997; Kratzer and Vrbancich, 2007).

Even during winter, there is usually some open water along the flight track, with an ice thickness of $0 \mathrm{~m}$ (Figs. 7 and 10). These open water sections are important for the verification of a correct drift correction
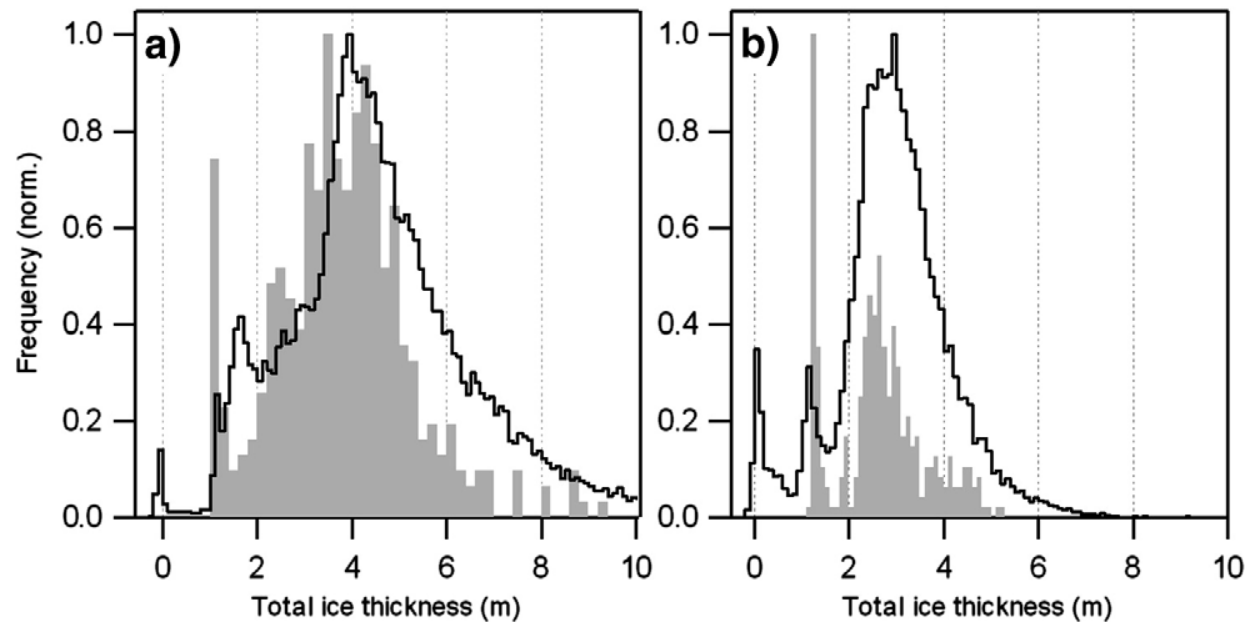

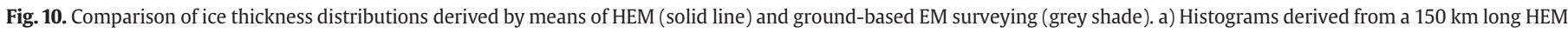

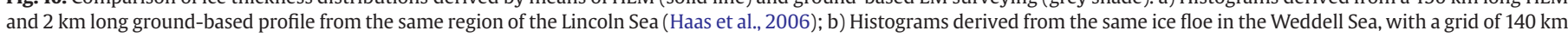
of HEM data and $4 \mathrm{~km}$ of ground-based data (Haas et al., 2008). 
and calibration, as the estimated ice thickness has to be $0 \mathrm{~m}$ over these regions as well. When there is no open water, drift, gain, and phase should be within the range of adjacent profile sections. The sensitivity study presented here (Section 6) shows that this can be done with little error.

Figs. 4 and 6 point to problems with spikes and strong drift of the high frequency of $112 \mathrm{kHz}$. That frequency is technically challenging because it exceeds the normal audio frequency range and therefore standard electronic components operate close to their technical limits. This is unfortunate, as the Inphase of the high frequency is superior in the case of measurements over brackish water. We have successfully measured ice thickness with sea water conductivities as low as $300 \mathrm{mS} / \mathrm{m}$ (Haas, 2004, 2006). The combination of frequencies of 3.68 and $112 \mathrm{kHz}$ is also sensitive to the bathymetry of shallow, brackish water (Haas, 2006).

Unfortunately, the performance of the high frequency measurements is also hampered by the low dipole moment and small coil spacing (Table 1). The former is due to the high AC resistance of coils at those frequencies. In fact, for even better sensitivity to ice conductivity, our original goal was to design $f 2$ as high as $200 \mathrm{kHz}$. However, no useful signals could be generated at this frequency at all. Although coil spacing was optimized for both frequencies, it is of course largely confined by the small size of the bird, which poses a great constraint. In fact, a small increase in coil spacing from 2.7 to $3.5 \mathrm{~m}$ would double the in-phase sensitivity of $f 1$ (Pfaffling et al., 2007).

Due to the great success of our bird operations, we have actually built a second bird. This operates only at one frequency of $4.1 \mathrm{kHz}$, but is otherwise identical to the first bird. Its behaviour and performance are very similar to that of the first bird presented here.

Future improvements of the birds should include means for measuring the exact bird orientation and pitch and roll, e.g. with several differential GPS antennas (Holladay et al., 1997) or with an inertial navigation system. Combination with a radar for snow thickness measurements would also be desirable (Lalumiere, 1998), as snow is an independent climate variable and strongly influences sea ice thermodynamics.

Although we operate our bird several times per year and also for systematic ice thickness monitoring projects, it should not be forgotten that most accurate results can only be obtained over level ice, and that conclusions from this paper are also only valid for level ice. For a better judgment of the bird performance over deformed and porous ice with a 3D structure, coincident measurements of the true underside topography are required. These can be obtained by upwardlooking sonar measurements with submarines or autonomous underwater vehicles, or by divers. During the present International Polar Year (IPY) in 2007 and 2008, we are very hopeful to obtain an extensive coincident underwater and EM ice thickness data set.

\section{Acknowledgements}

We are most grateful to E. Augstein and H. Miller for initiating this work, and for funding and continued support by the Alfred Wegener Institute. K.P. Sengpiel and the staff of Aerodata AG and Optimare Sensorsysteme AG are greatly acknowledged for their geophysical and technical guidance and advice. Numerous students improved the data processing procedures. We also acknowledge the patience and cooperation of pilots and staff of Helicopter Service Wasserthal and Helitransair during extensive tests flights. Careful comments of James Macnae and the Editor Niels B. Christensen improved the manuscript significantly.

\section{References}

Fitterman, D.V., 1998. Sources of calibration errors in helicopter EM data. Exploration Geophysics 29, 65-70.

Fitterman, D.V., Yin, C., 2004. Effect of bird maneuver on frequency-domain helicopter EM response. Geophysics 69 (5), 1203-1215. doi:10.1190/1.1801937.
Haas, C., 1998. Evaluation of ship-based electromagnetic-inductive thickness measurements of summer sea-ice in the Bellingshausen and Amundsen Seas, Antarctica. Cold Regions Science and Technology 27, 1-16.

Haas, C., 2003. Dynamics versus thermodynamics: the sea-ice thickness distribution. In: Thomas, D.N., Dieckmann, G.S. (Eds.), Sea Ice-An Introduction to its Physics, Biology, Chemistry and Geology. Blackwell Scientific, pp. 82-111.

Haas, C., 2004. Airborne EM sea-ice thickness profiling over brackish Baltic sea water. Proceedings of the 17th international IAHR Symposium on Ice, June 21-25, 2004, 2. All-Russian Research Institute of Hydraulic Engineering (VNIIG), Saint Petersburg, Russia, pp. 12-17.

Haas, C., 2006. Airborne electromagnetic sea ice thickness sounding in shallow, brackish water environments of the Caspian and Baltic Seas. Proceedings of OMAE2006 25th International Conference on Offshore Mechanics and Arctic Engineering. Hamburg, Germany. 6 pp.

Haas, C., Jochmann, P., 2003. Continuous EM and ULS thickness profiling in support of ice force measurements. Proceedings of the 17th International Conference on Port and Ocean Engineering under Arctic Conditions POAC '03, 2. Department of Civil and Transport Engineering, Norwegian University of Science and Technology NTNU, Trondheim, Norway, pp. 849-856.

Haas, C., Gerland, S., Eicken, H., Miller, H., 1997. Comparison of sea-ice thickness measurements under summer and winter conditions in the Arctic using a small electromagnetic induction device. Geophysics 62, 749-757.

Haas, C., Hendricks, S., Doble, M., 2006. Comparison of the sea ice thickness distribution in the Lincoln Sea and adjacent Arctic Ocean in 2004 and 2005. Annals of Glaciology, 44, 247-252.

Haas, C., Nicolaus, M., Willmes, S., Worby, A.P., Flinspach, D., 2008. Sea ice and snow thickness and physical properties of an ice floe in the western Weddell Sea and their changes during spring warming. Deep Sea Research II 55 (8-9), 963-974. doi:10.1016/j.dsr2.2007.12.020.

Hall, A., 2004. The role of surface albedo feedback in climate. Journal of Climate 17, 1550-1568.

Holladay, J.S., Lo, B., Prinsenberg, S.J., 1997. Bird orientation effects in quantitative airborne electromagnetic interpretation of pack ice thickness sounding. Conference Proceedings of the Oceans Conference 1997, 2. Marine Technology Society, Institute of Electrical and Electronics Engineers Inc., pp. 1114-1119.

Kovacs, A., Holladay, J.S., 1990. Sea-ice thickness measurements using a small airborne electromagnetic sounding system. Geophysics 55, 1327-1337.

Kovacs, A., Valleau, N.C., Holladay, J.S., 1987. Airborne electromagnetic sounding of sea ice thickness and sub-ice bathymetry. Cold Regions Science and Technology 14, 289-311.

Kovacs, A., Holladay, J.S., Bergeron, C.J., 1995. The footprint/altitude ratio for helicopter electromagnetic sounding of sea-ice thickness: comparison of theoretical and field estimates. Geophysics 60, 374-380.

Kratzer, T., Vrbancich, J., 2007. Real-time kinematic tracking of towed AEM birds. Exploration Geophysics 38, 132-143. doi:10.1071/EG07012.

Lalumiere, L.A., 1998. Implementation of a prototype real-time snow thickness radar. Canadian Contractor Report of Hydrography and Ocean Sciences 4881 pp.

Liu, G., Becker, A., 1990. Two-dimensional mapping of sea ice keels with airborne electromagnetics. Geophysics 55, 239-248.

Liu, G., Kovacs, A., Becker, A., 1991. Inversion of airborne electromagnetic survey data for sea-ice keel shape. Geophysics 56, 1986-1991.

Maykut, G.A., 1986. The surface heat and mass balance. In: Untersteiner, N. (Ed.), The Geophysics of Sea Ice. Martinus Nijhoff Publ., Dordrecht, pp. 395-463 (NATO ASI B146).

Meier, W., Stroeve, J., Fetterer, F., Knowles, K., 2005. Reductions in arctic sea ice cover no longer limited to summer. Eos, Transactions of the American Geophysical Society 86, 326.

Multala, J., Hautaniemi, H., Oksama, M., Leppäranta, M., Haapala, J., Herlevi, A., Riska, A., Lensu, M., 1996. An airborne electromagnetic system on a fixed wing aircraft for sea ice thickness mapping. Cold Regions Science and Technology 24, 355-373.

Pfaffling, A., Reid, J.E., 2009. Sea ice as an evaluation target for HEM modelling and inversion. Journal of Applied Geophysics 67, 242-249 (this issue).

Pfaffling, A., Haas, C., Reid, J.E., 2007. A direct helicopter EM sea ice thickness inversion, assessed with synthetic and field data. Geophysics 72, F127-F137.

Prinsenberg, S.J., Holladay, J.S., 1993. Using air-borne electromagnetic ice thickness sensor to validate remotely sensed marginal ice zone properties. In: HSVA (Ed.), Port and Ocean Engineering under Arctic Conditions (POAC 93), 2, pp. 936-948.

Prinsenberg, S.J., Holladay, J.S., Lee, J., 2002. Measuring ice thickness with EISFlowTM, a fixed-mounted helicopter electromagnetic-laser system. Proceedings 12th International Offshore and Polar Engineering Conference, 1, pp. 737-740.

Reid, J., Pfaffling, A., Vrbancich, J., 2006. Airborne electromagnetic footprints in onedimensional earths. Geophysics 71 (2), G63-G72. doi:10.1190/1.2187756.

Rossiter, J.R., Holladay, J.S., 1994. Ice-thickness measurement. In: Haykin, S., Lewis, E.O., Rainey, R.K., Rossiter, J.R. (Eds.), Remote Sensing of Sea Ice and Icebergs. John Wiley \& Sons Inc., pp. 141-176.

Rothrock, D.A., Yu, Y., Maykut, G.A., 1999. Thinning of the Arctic sea-ice cover. Geophysical Research Letters 26, 3469-3472.

Stroeve, J., Serreze, M.C., Fetterer, F., Arbetter, T., Meier, W., Maslanik, J., Knowles, K., 2005. Tracking the Arctic's shrinking ice cover; another extreme September sea ice minimum in 2004. Geophysical Research Letters 32, L04501. doi:10.1029/2004GL021810.

Wadhams, P., 2000. Ice in the Ocean. Gordon \& Breach Science Publishers. 351 pp.

Ward, S.H., Hohmann, G.W., 1988. Electromagnetic theory for geophysical applications. In: Nabighian, M.N. (Ed.), Electromagnetic Methods in Applied Geophysics, Volume 1 Theory. SEG Monograph, vol. 3, pp. 131-313. 